\title{
An experimental philosophical bioethical study of how human rights are applied to clitorectomy on infants identified as female and as intersex
}

\section{Annette Smith \& Peter Hegarty}

To cite this article: Annette Smith \& Peter Hegarty (2020): An experimental philosophical bioethical study of how human rights are applied to clitorectomy on infants identified as female and as intersex, Culture, Health \& Sexuality, DOI: $10.1080 / 13691058.2020 .1788164$

To link to this article: https://doi.org/10.1080/13691058.2020.1788164

View supplementary material $₫$

Published online: 04 Sep 2020.

Submit your article to this journal $\llbracket$

Q View related articles $\sqsubset$

View Crossmark data $\nearrow$ 


\title{
An experimental philosophical bioethical study of how human rights are applied to clitorectomy on infants identified as female and as intersex
}

\author{
Annette Smith (D) and Peter Hegarty \\ School of Psychology, University of Surrey, Guildford, UK
}

\begin{abstract}
Clitorectomies performed on the genitals of infants identified as female and as intersex have been described both as similar procedures and as different procedures. The former types of surgery have been recognised more consistently as human rights abuses than the latter in recent decades. We tested social psychological explanations of why human rights are differently recognised when infants are described as 'intersex' or 'female'; 122 laypeople in the UK read one of two near-identical descriptions of clitorectomies performed on intersex or female infants and reported their agreement with 22 items about the human rights of such infants. Clitorectomies were perceived as violating human rights more by women than by men, and more so when infants were described as female than intersex. Endorsement of human rights was better predicted by several psychological variables when infants were described as female than as intersex. Less politically conservative participants, as assessed by a Right-Wing Authoritarianism measure, and participants who trusted medical authority more recognised human rights violations of female infants more than intersex infants. Results are discussed with respect to human rights efforts to protect infants from medically non-necessary genital surgery on the basis of membership in identity categories or possession of sex characteristics.
\end{abstract}

\section{ARTICLE HISTORY}

Received 7 February 2020

Accepted 23 June 2020

\section{KEYWORDS}

Intersex; FGM; public opinion; human rights; clitorectomy

\section{Introduction}

In an early paper on the first wave of intersex patient activism, Cheryl Chase (1998) made a historical point about the legitimacy of conducting clitorectomy (the surgical removal, partial removal or reduction of the size of a clitoris) on infants. In the 1960s, as more children with congenital adrenal hyperplasia survived infancy with cortisol injections, surgeons increasingly performed clitorectomies on children with congenital adrenal hyperplasia, identified as girls, to normalise their appearance. In this historical context, medical researchers sometimes compared modern Western medical clitorectomies on girls with congenital adrenal hyperplasia to traditional African clitorectomy

CONTACT Annette Smith as01233@surrey.ac.uk

(1) Supplemental data for this paper can be accessed here. 
(see e.g. Gross, Randolph and Crigler 1966). Their reasoning was that as the two forms of clitorectomy were analogous, and since African clitorectomies were long standing, that modern Western clitorectomies on intersex infants were also acceptable.

Writing just after the first laws against female genital mutilation in the USA criminalised female genital mutilation in 1996, Chase (1998) noted that intersex doctors now seemed keen to distinguish their own modern Western practices from traditional African ones. As Chase argued elsewhere, Western surgical practices were increasingly described as 'clitoral recession' rather than 'clitorectomy' (also called 'clitoridectomy') and the material basis for the rhetorical distinction might be smaller than it appears. "'-Ectomy" means "to cut" - if you cut on something, it's an -ectomy' (Hegarty and Chase 2000, 124).

Over the past twenty years, modern Western surgical practices of cutting on clitoral tissues of infants that are larger than is typically the case for infant girls have remained at the centre of debates about the medicalisation of variable sex characteristics (see Liao et al. [2019] for discussion). The terms 'intersex traits' and 'disorders of sex development' have also applied to diverse bodily variations in the social science disciplines and the biomedical disciplines respectively (see Lundberg, Hegarty and Roen [2018] for discussion). In the early 2000s, studies of adult women with variable sex characteristics who had undergone clitoral surgeries in childhood evidenced clear iatrogenic harms such as higher rates of non-sensuality and lower ability to achieve orgasm (Minto et al. 2003) as well as poor cosmetic outcome and the need for follow-up surgery (Creighton, Minto and Steele 2001). Risks of such iatrogenic harms were acknowledged by the landmark Consensus Statement on Management of Intersex Disorders (Lee et al. 2006).

One might have expected a rapid reduction in clitoral surgery in this patient group following this recognition in the Consensus Statement. However, a study of the statement's effects in Europe found that only of half of the disorders of sex development multidisciplinary teams surveyed reported a reduction in rates of clitoral surgery (Pasterski, Prentice and Hughes 2010). UK National Health Service data show no change in rates of clitoral surgery on girls following the Chicago Consensus Statement (Michala et al. 2014). In the USA, genitoplasty is chosen for infants with a range of variable sex characteristics far more often than it is refused (Ellens et al. 2017). A recent interview study of 32 medical, surgical, psychological and nursing professionals and clinical scientists from 12 British and Swedish specialist multidisciplinary care centres for individuals diagnosed with a genetic condition associated with differences of sex development (Liao et al. 2019) showed that European DSD professionals were aware that clitoral surgery for VSC was controversial, yet continued to rely on social 'normalizing' justifications for it The authors suggested that a social psychological dynamic of 'pluralistic ignorance' (see Prentice and Miller 1996) may operate in disorders of sex development multidisciplinary teams, such that all teams construct their own team as doing less aggressive surgery than is the norm in clinical practice.

Over the last twenty years, laws against female genital mutilation have become stronger in the Western context, creating greater distance between the protection from surgery for children who might be categorised as female and those categorised as intersex or diagnosed with a disorder of sex development on the basis of having variable sex characteristics. In the UK, where the present study was conducted, the 
Female Genital Mutilation Act (2003) defines female genital mutilation as occurring when someone 'excises, infibulates or otherwise mutilates the whole or any part of a girl's labia majora, labia minora or clitoris'; the Act excludes genital cutting enacted by an approved healthcare professional for a woman's mental or physical health, or during labour, but not cutting enacted for reasons of 'ritual' or 'custom' (chapter 31, section 1). Like many laws against genital mutilation, the 2003 UK Act applies only to girls and women, and such restrictions to one gender category have recently made such laws vulnerable to challenge (Earp, forthcoming). The 2006 USA Act that banned female genital mutilation and set the context for Chase's early writings has been struck down in a recent case. The genital surgery that prompted the case was conducted by a physician in a clinical environment on a girl who was a member of the Dawoodi Bohra community (Earp, forthcoming). In this community, male genital cutting can very plausibly be argued to be more physically invasive than the form of female genital cutting that is practised. Judge Bernard A. Friedman described the law which protected only girls as failing to satisfy requirements for non-discrimination on the basis of sex. However, as Earp (forthcoming) points out, he struck down the law on the basis of the federalist principle that the national government does not have the authority to regulate 'local criminal activity' (here, physical assault).

This development has informed recent discussion of the bioethics of genital surgery on infants that seeks to conceptualise the bodily integrity of female, intersex and male infants under similar principles (see The Brussels Collaboration on Bodily Integrity 2019). This is a shift away from understanding the grounds for protection from harmful surgery from the social identity of being a girl/woman towards the severity of harm to sex characteristics risked by intervention. This shift away from identity categories resonates with concerns about the 10-year update to the Yogyakarta Principles (Yogyakarta Principles 2017) whose authors emphasise human rights protection on the basis of sex characteristics rather than intersex identity (Carpenter, forthcoming). Young people with variable sex characteristics less often construct variable sex characteristics as an intersex social identity than laypeople might predict, sometimes describing it as 'only part of me' (Lundberg et al. 2016, 340).

The present study aims to describe how lay people apply human rights thinking to clitorectomies on female vs intersex infants, and which individual differences in psychological attitudes and beliefs might moderate that application. We build on a small body of psychology experiments (see Streuli et al. 2013; Hegarty, Smith and BoganCarey 2019) that have manipulated features of information to demonstrate their effects on beliefs and decisions about surgical interventions on children's variable sex characteristics. We contribute to what Earp et al. (2020) have recently described as experimental philosophical bioethics: an interdisciplinary approach employing empirical methods to advance theoretical debates. Kessler (1998) asked young women, who were not parents, to consider a hypothetical choice about clitorectomy for a daughter just born with a larger-than-typical clitoris, or to consider that their parents had earlier faced the same decision regarding those young women themselves. Most participants chose surgery for their daughter, but most also reported that they would have wanted their parents to reject the surgery option for themselves. Streuli et al. (2013) asked trainee medical professionals to consider a hypothetical surgery decision about a child 
with variable sex characteristics. Most chose surgery when the information was presented through medical language, but most rejected it when it was presented through non-medical psychological language. Hegarty, Smith and Bogan-Carey (2019) asked psychology students to view YouTube videos in which intersex people spoke from experience, leading to more negative beliefs about the effects of medicine when intersex speakers presented a social identity framing rather than a medicalised framing of life experience with variable sex characteristics. Such studies respond to Liao and Simmonds' (2014) call to study lay understandings of intersex/disorders of sex development and heighten concerns arising from interview studies that disorders of sex development professionals' personal assessments about psychosocial factors inform their discourse about which interventions are necessary and which are in their patients' best interests (e.g. Liao et al. 2019; Roen et al. 2018; Roen and Hegarty 2018).

\section{This study}

In dialogue with such bioethical opinion, the first aim of this experimental study was to test the hypothesis that lay people would consider clitorectomies to infringe human rights less when performed on infants nominated as 'intersex' rather than 'female'. Earp et al. (2020) have argued that experimental philosophical bioethics can particularly reveal the psychological mechanisms and situational factors that shape normative bioethical judgements. To date, such experimental studies have focused on perspective taking (Kessler 1998) and variably medicalised framing of information (Hegarty, Smith and Bogan-Carey 2019; Streuli et al. 2013). But bioethicists have also claimed that variable sex characteristics are not always culturally recognised as prototypical human tissues, and that this failure of recognition leads to the failure to recognise non-necessary medical intervention on variable sex characteristics as infringing human rights (Feder 2014). These views motivated our primary hypothesis.

Our second aim was to explore five psychological constructs that might point to 'mechanisms' (Earp et al. 2020) that might sustain beliefs that clitorectomy is similarly or differentially infringing of human rights when conducted on infants who are described as 'intersex' vs 'female'. We describe these five constructs next.

Beliefs in gender binary was the first psychological construct. Some of the earliest social science on intersex pointed to a 'natural attitude' that gender is a binary category rooted in anatomical difference (Garfinkel 1967). Tee and Hegarty (2006) developed an individual differences measure that assesses these beliefs. In a recent survey of UK and US adults, Hegarty et al. (forthcoming) found variation in endorsement of early surgical interventions, in legal protections of human rights that such interventions might risk, and in a range of supports for people with intersex traits from parents, support groups and government policies. Support for medical intervention was strongly predicted by belief in the gender binary as measured by Tee and Hegarty's (2006) measure. These findings suggest that people who score high on a measure of gender binary beliefs might particularly consider clitorectomy more legitimate when conducted on intersex than female infants, as they have less regard for the inherent value of sex characteristics that make bodies seem different from binary norms. 
The second construct we measured was beliefs in medical authority. As the introduction makes clear, Western medical authorities have constructed both similarities and differences between Western and African clitorectomies to describe clitorectomies on variable sex characteristics as benevolent. Trust in the benevolence of medical authority can sustain a perception that cutting in medicalised environments does not infringe human rights. Hegarty et al. (forthcoming) developed a face valid measure of belief in medical authority and found it to predict support for surgery on infants' intersex characteristics. However, its relationship to support for surgery on female infants has not been assessed.

The third construct that we assessed was related to colonial beliefs. In 'minority world' countries (Alam 2008) such as the UK, female genital mutilation is often stereotyped as a barbaric and backward practice that is peculiar to third world societies (Arora and Jacobs 2016). Guiné and Fuentes (2007) found that differences in female genital mutilation prevention strategies between the UK and France were contingent on acceptance of ethnic minorities as a 'colonial inheritance'. Measures of this ideology are not common in psychology, but one subscale of David and Okazaki's (2006) colonial mentality scale, which was developed for the Filipino American population, measures belief in colonial debt. Adapting this scale to this cultural context allowed us to test the hypothesis that clitorectomies on intersex vs female infants would seem most different to participants who most believed that formerly colonised African groups were most indebted to their former UK colonisers.

Fourth, we utilised the tolerance for ambiguity subscale from the need for closure scale (Roets and Van Hiel 2011). Need for closure is a psychological orientation towards firm answers to questions and aversion to ambiguity (Kruglanski 1996). It is associated with political conservatism (Jost et al. 2003) and occupational stress among healthcare professionals (lannello et al. 2017). Surgery on infants' variable sex characteristics has long been described as a response to parental anxiety, whilst deferring such interventions seems to demand considerable tolerance for uncertainty (Karkazis 2008; Roen 2008, 2019; Roen and Hegarty 2018). Hegarty et al. (forthcoming) found intolerance for ambiguity to predict greater support for surgical intervention on infants' variable sex characteristics and greater support for social support for people with those same characteristics.

Finally, we investigated right-wing authoritarianism, a desire for social cohesion and security that predisposes people to submit to authority (Altemeyer 1981). Some authors argue that right-wing authoritarianism is composed of two or three statistically distinct factors (Rattazzi, Bobbio and Canova 2007; Mavor, Louis and Sibley 2010). High right-wing authoritarianism engenders prejudice towards LGBT groups (Crawford et al. 2016; Norton and Herek 2013), prejudice towards people with mental and physical health conditions (Crowson, Brandes and Hurst 2013; Fodor 2006), and tolerance of human rights violations (Benjamin 2016; Moghaddam and Vuksanovic 1990). Hegarty et al. (forthcoming) found that right-wing authoritarianism predicted tolerance of surgery on infants' variable sex characteristics and opposition to its legal regulation. These findings prompt competing predictions. First, high right-wing authoritarianism participants might consider all clitorectomies more legitimate because all such interventions risk infringing human rights. Second, high right-wing authoritarianism 
participants may conceive of these practices as different because clitorectomies on 'female' infants have been de-legitimised by legal authority whilst clitorectomies on 'intersex' infants have not.

\section{Method}

\section{Development of colonial debt scale}

A pilot study assessed the validity and reliability of a colonial debt scale adapted for this context. Fifty-five women and twenty men aged $18-56$ years $(M$ age $=32.27$ years, $S D=9.32$ ) were recruited via opportunity sampling online and completed all the items. All were British, and they reported ethnicity as White/Caucasian British $(n=68)$, British $(n=5)$ and Black/Mixed race British $(n=3)$. Participants completed seven items adapted from David and Okazaki (2006), from the Filipino American context to a British population. For example, the original item 'Filipinos should feel privileged and honoured that Spain and the United States had contact with them' was adapted to: 'People from former British Overseas Territories should feel privileged and honoured that the United Kingdom had contact with them' (see Appendix A in online supplemental materials for original and adapted items). The study included the required ratio of 10 participants to item assessed (Nunnally and Bernstein 1978). All were presented in 7-point attitude items ranging from 1 'strongly disagree' to 7 'strongly agree'. Higher scores indicated tolerating or minimising historical and contemporary oppression of African cultures as an appropriate cost of civilisation.

Overall scores were significantly lower than the midpoint of the scale, $M=3.07$, $S D=1.25$, one-sample $t(74)=-6.48, p<.001$, and normally distributed (skewness $=$ $0.31, S E=0.28$; and kurtosis $=-0.62, S E=0.55$ ). Kaiser-Meyer-Olkin measure of sampling adequacy was .87. Factor analysis revealed one component with Eigenvalue 4.39 explaining $62.7 \%$ of the variance in responses to the seven items. A single 7-item scale was found to be highly reliable ( 7 items; $\alpha=.89$ ). All seven adapted items were retained to measure colonial debt in the main study.

\section{Participants}

A priori power analysis using $\mathrm{G}^{*}$ power projected that a sample size of 128 participants was needed to detect a medium effect size $(d=0.5)$, with an alpha of .05 and statistical power of 0.80 (Faul and Erdfelder 2004). A total of 128 British participants were therefore recruited. After screening out six participants who were not British, younger than 18, or withheld final consent, 58 women, 63 men and one non-binary participant were retained for analyses $(M$ age $=30.60, S D=11.70$, range $=18-61$ years). They reported their ethnicity as White $(n=109)$, Asian/Asian British $(n=7)$, Black/Black British $(n=3)$, Mixed ethnic $(n=2)$ or Other/prefer not to say $(n=1)$. They reported religion as None $(n=74)$, Christian $(n=23)$, Hindu $(n=3)$, Muslim $(n=2)$, Buddhist $(n=1)$, Jewish $(n=1)$ or Other/prefer not to say $(n=18)$. Sexual orientation was reported on a 7-point scale from 1 'exclusively heterosexual' to 7 'exclusively homosexual', and the sample was predominantly heterosexual $(M=2.05, S D=1.88)$. Participants reported their highest educational level as GCSE $(n=9)$, A-level $(n=45)$, 
undergraduate $(n=49)$ or doctorate degree $(n=19)$. Political views were assessed on a 7-point scale from 1 'left-wing' to 7 'right-wing'. One participant did not complete this item, and the sample was otherwise significantly more left-wing than the middle of the scale $(M=3.08, S D=1.38)$, one-sample $t(120)=-7.30, p<.001$. Participants were recruited online through Prolific, a participant recruitment platform, and through opportunity sampling via email. Prolific users were awarded $£ 1$ for their participation.

\section{Materials}

Participants invited to this online study on 'genital surgeries performed on infants' read a short recruitment text, which warned the survey 'includes potentially upsetting content on a sensitive topic', before activating the survey link. Participants who activated the survey link completed a participant information sheet, a consent form and short introduction to controversies around infant genital surgery.

Participants read one of two very similar texts that introduced clitoridectomy on infants, and differed only in (1) their reference to 'intersex' or 'female' genitals, and (2) the addition of a first clarifying definition of 'intersex' in the intersex text:

[Intersex people are born with variations in sex characteristics that do not fit the typical definitions for male or female bodies]. Female Genital Procedures (FGP)/Intersex Genital Procedures (IGP)] are performed on infants and children worldwide, for many reasons. These reasons include 'normalising' appearance to conform to cultural norms and to prepare children for sexual adulthood in cultural contexts. These surgical practices are called clitoridectomies when they involve cutting on the clitoris, and they are sometimes conducted in NHS hospitals. Clitoridectomies are the most controversial surgical practices among these genital procedures. These procedures are often undertaken by medical professionals, often with a parent or guardian's consent, as children are often too young to consent to the procedures themselves. There is considerable debate about whether these controversial surgeries should be performed now.

These two texts operationalised the independent variable, and Qualtrics survey software randomly assigned participants to the intersex or female genital surgery conditions in which the relevant texts were presented.

Next the measures of support for human rights were presented. We created 22 statements - adapted from research literature, consensus statements and legal documents (see Appendix B in online supplemental material) - and presented each as a 7point item ranging from 1 'strongly disagree' to 7 'strongly agree'. Items varied by condition only by referring to 'intersex infants' or 'female infants', consistent with experimental condition. We constructed items that assessed five dimensions of human rights concern. Five items assessed parents' rights to make surgical decisions in infant children's best interests (e.g. 'Parents do not always know what medical procedures are best for their own child', reverse-coded item). Because the human rights to bodily integrity are held to inhere in the child themselves, parents' rights to make decisions about medical intervention are somewhat at odds with children's rights. Four items assessed rights to bodily integrity (e.g. 'States must act to guarantee and protect the rights of all children to bodily integrity'). Four items assessed children's open future rights (e.g. 'These surgeries violate an individual's right to personal autonomy over their own future'). Five items assessed belief in long-term physical and mental health 
consequences (e.g. 'After [Intersex/Female] Genital Procedures, people report normal sexual function', reverse-coded item). Four items address rights as defined by the United Nations Universal Declaration of Human Rights (UN General Assembly 1948) ('I think that these genital surgeries on children infringe their human rights'). Items were reverse-coded as appropriate, and averaged to create a single measure of support for human rights.

Two items reduced reliability in one or other conditions and were removed. One assessed bodily integrity ('children do not need a sensate clitoris, as a penetrable vagina is all that is strictly necessary for a functional female'), and the other assessed parental rights ('It is health care providers' duty to support the parents' choices for or against genital surgery'). Items indicating support for parental rights to decision making were negatively correlated with all other items assessing support for other rights. The remaining twenty items were averaged to form a single reliable measure of support for human rights $(\alpha=.89$ in both conditions, see Appendix $B$ in online supplemental material for all items, reverse-coding information and further reliability statistics).

We next presented five standard psychological scales to measure five variables of interest. All items were presented on all scales in 7-point format with responses ranging from 1 'Strongly Disagree' to 7 'Strongly Agree', and all were reliable in this sample. In order of their presentation, these scales were our adapted seven-item colonial debt scale ( $\alpha=.93$ ), Tee and Hegarty's (2006) Gender Binary Beliefs measure ( $\alpha=.89$, 9 items), the items from Rattazzi, Bobbio and Canova's (2007) Right-Wing Authoritarianism scale, which yielded reliable subscales of Aggression/Submission ( $\alpha=$ .94, 7 items) and Conservatism ( $\alpha=.83,7$ items), Roets and Van Hiel's (2011) Tolerance for Ambiguity items from the Need for Closure scale ( $\alpha=.81,9$ items) and the Belief in Medical Authority scale developed by Hegarty et al. (forthcoming) ( $\alpha=$ $.72,6$ items). Finally, participants reported demographic information.

\section{Procedure}

Participants who responded to the call worked through the study materials online at a time and place of their own choosing. Participants were randomly assigned to text condition by the Qualtrics software. After completing the study, they read a written debrief on the aims of the study and were asked for final, informed consent, invited to provide feedback and signposted to support groups and websites.

\section{Results}

We tested the main hypothesis that support for human rights would be greater in the context of female than intersex genital surgery using a $2 \times 2$ ANOVA with experimental condition (intersex vs female) and participant gender (man vs woman) as independent between-subjects variables. Support for human rights was high, and we observed two significant main effects that qualified that support. First, as predicted, support for human rights was significantly lower in the intersex condition $(M=5.71$, $S D=0.92)$ than in the female condition $(M=6.07, S D=0.86), F(1,117)=3.91, p=.05$, 
Table 1. Correlation between support for human rights and psychological variables by infant surgery condition.

\begin{tabular}{lcccccrr}
\hline & 1 & 2 & 3 & 4 & 5 & 6 & 7 \\
\hline 1. Global Rights & & -.135 & -.235 & -.223 & $-.098^{*}$ & .091 & -.181 \\
2. Colonial Debt & $-.125^{*}$ & & $.504^{* *}$ & $.835^{* *}$ & .192 & .207 & .011 \\
3. Gender Binary & $-.327^{* *}$ & $.292^{*}$ & & $.563^{* *}$ & $.317^{*}$ & $.319^{*}$ & -.006 \\
4. RWA-A & $-.401^{* *}$ & $.399^{* *}$ & $.410^{* *}$ & & .214 & $.332^{*}$ & -.033 \\
5. RWA-C & $-.582^{* *}$ & .081 & $.326^{* *}$ & $.493^{* *}$ & & .064 & -.178 \\
6. Tolerance for Ambiguity & .059 & .188 & .175 & .204 & -.038 & & -.214 \\
7. Belief in Medical Authority & $.336^{* *}$ & -.122 & .003 & -.145 & $-.345^{* *}$ & $.252^{*}$ & \\
\hline
\end{tabular}

Note. Intersex condition above the diagonal $(n=57)$, female condition below the diagonal $(n=64)$.

RWA-A = Right-Wing Authoritarianism (Aggression Subscale), RWA-C = Right-Wing

Authoritarianism (Conservatism Subscale), ${ }^{*} p<.05,{ }^{* *} p<.01$.

$\eta_{p}{ }^{2}=.03$. Second, there was a larger significant main effect of participant gender $F(1,117)=6.06, p=.015, \eta_{p}{ }^{2}=.05$, as men $(M=5.70, S D=0.98)$ endorsed rights across the experiment less than women did $(M=6.12, S D=0.76)$. The one non-binary gender participant was not included in this analysis. As these two main effects did not interact, $F(1,121)=0.07, p=.80$, we analysed data from all participants together in the further analysis.

We next explored the psychological measures as predictors of this different support for female vs intersex infants' rights. Table 1 shows Pearson correlations between support for human rights and the five psychological predictors by condition. Five of the six psychological variables predicted support for human rights in the female condition, but none did in the intersex condition. Fisher $Z$ tests examined where the correlation between support for human rights and each of the five psychological variables varied significantly by condition. Right-wing authoritarianism-conservatism was significantly negatively correlated with support for human rights in both conditions, but the correlation was significantly weaker in the intersex condition than in the female condition, Fisher $Z=3.01, p<.001, Z=-3.02, p=.003$. Support for human rights was positively correlated with belief in medical authority in the female condition only, and this correlation also varied between conditions, $Z=2.89, p=.004$. All other tests of moderation were non-significant, all $|Z|<1.05$.

Support for human rights, by condition, is plotted against right-wing authoritarianism-conservatism in Figure 1, and against belief in medical authority in Figure 2. Participants who scored lower on right-wing authoritarianism-conservatism differentiated support for intersex and female infants' rights more than those who scored higher. Participants who scored higher on belief in medical authority differentiated support for intersex and female infants' rights more than those who scored lower.

\section{Discussion}

This contribution to experimental philosophical bioethics (Earp et al. 2020) evidences that human rights, as framed in research and policy, were more readily endorsed in regard to clitorectomies performed on female rather than intersex bodies. These predicted findings justify concerns of bioethicists and human rights advocates that variable sex characteristics may make a child vulnerable to non-necessary medical interventions and that protections on the basis of intersex identity may not address 


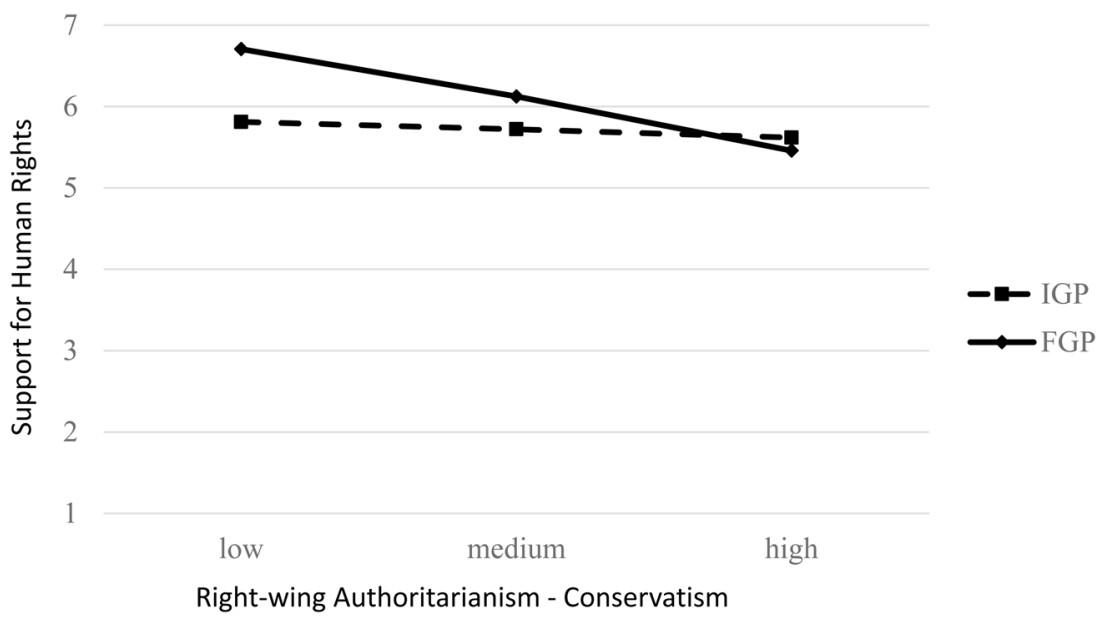

Figure 1. Support for Intersex and Female Infants' Human Rights as Moderated by RWA-Conservatism.

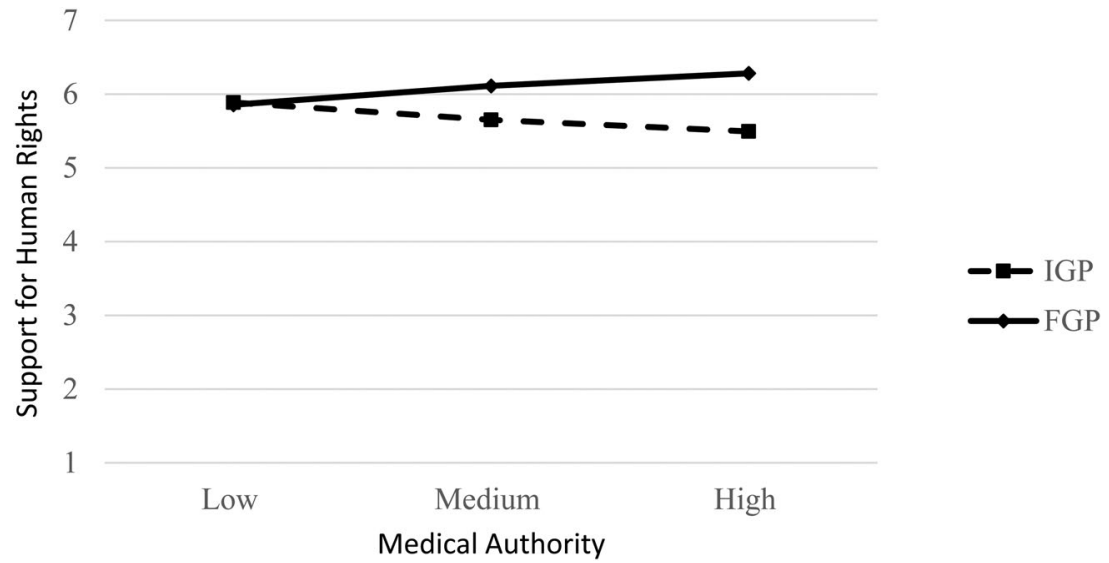

Figure 2. Support for Intersex and Female Infants' Human Rights as Moderated by Belief in Medical Authority.

this risk adequately (Carpenter, forthcoming). Participants were members of the UK public, with no particular prior expertise in this area.

The present study is a relatively unique contribution to philosophical experimental bioethics in this area because it examined how manipulating a sex category, rather than manipulating medicalised language, impacted opinions about a form of medicalisation. This original feature may explain two of this study's particular findings. First, women supported infants' human rights across contexts more than men did, and this difference was larger than the gender difference found in other studies (e.g. Hegarty et al., forthcoming). Differences in sampling practices across these two studies may account for the different sizes of this gender difference, but our consistent use of sexspecific terms for genital anatomy, such as 'clitoris' here, may also have made the vignettes more self-relevant to women than to men in both conditions. Second, by designating all infants as at least somewhat female through this language for genital 
anatomy, we may have suppressed the role of belief in the gender binary in predicting support for genital surgery on 'intersex' infants that emerged in other studies (Hegarty, Smith and Bogan-Carey 2019; Hegarty et al., forthcoming).

Several plausible psychological mechanisms could lead to a difference in the recognition of non-necessary surgery as an infringement of human rights. Exploration of five psychological variables here focused attention on conservatism and trust in medical authority in particular. Accordingly, these two constructs warrant more extensive discussion. Previous work on authoritarianism has focused on perceptions of human rights in conflict situations rather than medicalised environments, and has tended to alight on aggression, rather than conservatism, as the element of right-wing authoritarianism that grounds tolerance for human rights abuses in such contexts. Items on the right-wing authoritarianism (conservatism) scale here, which were all reversecoded, assessed attitudes towards religious authorities and tolerance towards freedoms expressed by atheists, feminists, homosexuals, nudists and young people. For example, one such reverse-coded item reads 'Homosexuals and feminists should be praised for being brave enough to defy "traditional family values"'. Given that achieving the recognition of female genital mutilation as human rights abuse has been a feminist project that has often opposed traditional religious authority sanctioning such practices, it is not surprising that participants in the 'female' condition who agreed with the right-wing authoritarianism-conservatism items more also recognised clitorectomy as infringing human rights more. The lack of an equivalent correlation in the 'intersex' condition may be a result of less public discussion of controversial surgeries on intersex genitals than female genital mutilation.

Clitorectomies on female vs intersex infants also seemed more similar to participants who believed more strongly in medical authority than to those who doubted it. This result is consistent with and informs previous findings that trust in medical authority predicts support for surgery on intersex traits (Hegarty et al., forthcoming) and framing experiments which have found that medicalised language engenders support for such surgery (Streuli et al. 2013). Multidisciplinary medical teams who specialise in disorders of sex development care can inadvertently 'frame' clitorectomy as necessary (Liao et al. 2019). This study suggests that parents who trust medical authority in general, might be most easily swayed by such inadvertent framing by healthcare professionals in such contexts.

\section{Future directions}

As noted in the introduction, there is a long history of medical and legal authorities and their critics of constructing clitorectomies on female and intersex genitals as equivalent and of constructing them as categorically different. What this study adds to intersex studies is a social psychological understanding of who, among the public, might be most likely to believe this rhetoric and why. We added to emerging findings that social psychological variables associated with political liberalism and scepticism of a medicalised conceptualisation of intersex are associated with rejecting the legitimacy of early surgical interventions (e.g. Hegarty et al., forthcoming).These findings respond 
to Liao and Simmonds' (2014) call for more studies of public understanding of intersex.

Because experiments are not a typical way of understanding the relationship between sexuality, culture and health, we conclude with some comments about how social psychological experiments can be useful in illuminating such understandings in intersex studies. Experimental social psychology and social constructionism are similarly grounded in a mutual interest in how people construe reality, and how those construals impact thoughts, feelings and actions to a greater extent than is consciously noticed or elaborated (Jost and Kruglanski 2002). Like Markus and Kitayama (2010), we understand experiments as an (admittedly individualist) window onto culturally particular constructions of personhood. Whilst experiments can be critiqued as apolitical on the basis of this individualism, they also provide a way to simulate social events that are hard to observe or rarely occur and to make inferences about such events (Spears and Smith 2001). A concern that might be raised about experimental philosophical bioethics is that social psychological experiments are not always replicated successfully (Open Science Collaboration 2012). We did not engage in all the best practices of open science here. For example, we did not pre-register our hypotheses, and, as such, this study should be regarded as somewhat exploratory and its conclusions tentative and subject to tests of replication. However, it is an advantage of experimental methods that they can be assessed for replication and can be extended. For example, the gender differences observed here might or might not emerge in a study that examines the application of human rights concepts to surgery on mild or severe hypospadic penises described in vignettes about 'male' or 'intersex' infants for example, or in a study that used less clearly 'gendered' language for genital anatomy.

Finally, experiments such as this one require incomplete disclosure of hypotheses to participants to avoid such biases as social desirability effects and reactance against the experimenter's hypothesis. As disclosure and deception are central to intersex bioethics, there is a relationship between the positivist methods that social psychological experiments use and the history of medicalisation that intersex studies must critically address. Consistent with modern ethics practices, we asked for participants' consent both prior to participation and after they had been debriefed about the study's design and full purpose. We also asked for open-ended comments on the experience of research participation. Nearly $10 \%$ of respondents chose to leave comments, which largely endorsed the research (e.g. 'Male or Female, no child should have to suffer GM. It's good work you're doing'). On the basis of this study's results and its participants' reflections it seems feasible, ethical and informative to connect empirical philosophical bioethics and public understanding of intersex, to consider how medicalisation might rationally retract to address human rights concerns. As Hegarty et al. (forthcoming) have recently argued, early surgery on variable sex characteristics has long been warranted on grounds that social stigma is unbearable, whilst social understanding of variable sex characteristics has rarely been empirically addressed. We hope this study contributes to a trend to replace fear and ignorance about public reactions to people with variable sex characteristics with measured social psychological understanding of support and opposition to such surgery, and to the people on whom surgery is brought to bear. 


\section{Disclosure statement}

No potential conflict of interest was reported by the author(s).

\section{ORCID}

Annette Smith (ID http://orcid.org/0000-0002-5349-7888

Peter Hegarty (D) http://orcid.org/0000-0002-5487-4075

\section{References}

Alam, S. 2008. "Majority World: Challenging the West's Rhetoric of Democracy." Amerasia Journal 34 (1): 88-98.

Altemeyer, B. 1981. Right-Wing Authoritarianism. Winnipeg: University of Manitoba Press.

Arora, K. S., and A. J. Jacobs. 2016. "Female Genital Alteration: A Compromise Solution." Journal of Medical Ethics 42 (3): 148-154.

Bauer, M., D. Truffer, and K. Plattner. 2014. "Intersex Genital Mutilations: Human Rights Violations of Children with Variations of Sexual Anatomy." In NGO Report to the 2nd, 3rd and 4th Periodic Report of Switzerland on the Convention on the Rights of the Child $(C R C)+$. Supplement Background Information on IGMs. http://intersex.shadowreport.org/public/2014-CRC-SwissNGO-Zwischengeschlecht-Intersex-IGM_v2.pdf

Beh, H. G., and M. Diamond. 2000. "An Emerging Ethical and Medical Dilemna: Should Physicians Perform Sex Assignment Surgery on Infants with Ambiguous Genitalia." Michigan Journal of Gender \& Law 7 (1): 1-63. http://heinonline.org/HOL/P?h=hein.journals/mjgl7\&i=11

Benjamin, A. J. Jr. 2016. "Right-Wing Authoritarianism and Attitudes toward Torture." Social Behavior and Personality 44 (6): 881-887.

Brussels Collaboration on Bodily Integrity. 2019. "Medically Unnecessary Genital Cutting and the Rights of the Child: Moving toward Consensus." The American Journal of Bioethics 19 (10): 17-28.

Carpenter, M. Forthcoming. "Intersex Human Rights and the Yogyakarta Principles Plus 10." Culture, Health \& Sexuality.

Chase, C. 1998. "Hermaphrodites with Attitude: Mapping the Emergence of Intersex Political Activism." GLQ: A Journal of Lesbian and Gay Studies 4 (2): 189-211.

Crawford, J. T., M. J. Brandt, Y. Inbar, and S. R. Mallinas. 2016. "Right-Wing Authoritarianism Predicts Prejudice Equally Toward 'gay men and lesbians' and 'homosexuals'." Journal of Personality and Social Psychology 111 (2): e31-e45.

Creighton, S. M., C. L. Minto, and S. J. Steele. 2001. "Objective Cosmetic and Anatomical Outcomes at Adolescence of Feminising Surgery for Ambiguous Genitalia Done in Childhood." The Lancet 358 (9276): 124-125.

Creighton, S. M., L. Michala, I. Mushtaq, and M. Yaron. 2014. "Childhood Surgery for Ambiguous Genitalia: Glimpses of Practice Changes or More of the Same?" Psychology \& Sexuality 5 (1): 34-43.

Crowson, H. M., J. A. Brandes, and R. J. Hurst. 2013. "Who Opposes Rights for Persons with Physical and Intellectual Disabilities?" Journal of Applied Social Psychology 43: E307-E318.

David, E. J.R., and S. Okazaki. 2006. "The Colonial Mentality Scale (CMS) for Filipino Americans: Scale Construction and Psychological Implications." Journal of Counseling Psychology 53 (2): 241-252.

Earp, B. D., J. Demaree-Cotton, M. Dunn, V. Dranseika, J. A. Everett, A. Feltz, G. Geller, et al. 2020. "Experimental Philosophical Bioethics." AJOB Empirical Bioethics 11 (1): 30-33.

Earp, B. D. Forthcoming. "Why was the U.S. ban on Female Genital Mutilation Ruled Unconstitutional, and What Does This Have to Do with Male Circumcision?" Ethics, Medicine, and Public Health. 
Ehrenreich, N., and M. Barr. 2005. "Intersex Surgery, Female Genital Cutting, and the Selective Condemnation of Cultural Practices." Harvard Civil Rights-Civil Liberties Law Review 40 (1): 71-140. http://ssrn.com/abstract=2926589

Ellens, R. E., D. M. Bakula, A. J. Mullins, K. J. Scott Reyes, P. Austin, L. Baskin, K. Bernabé, et al. 2017. "Psychological Adjustment of Parents of Children Born with Atypical Genitalia 1 Year after Genitoplasty." The Journal of Urology 198 (4): 914-920.

Faul, F., and E. Erdfelder. 2004. GPOWER: A Priori, Post-Hoc, and Compromise Power Analyses for MS-DOS [Computer Program]. Bonn: Bonn University, Department of Psychology.

Feder, E. K. 2014. Making Sense of Intersex: Changing Ethical Perspectives in Biomedicine. Bloomington: Indiana University Press.

Female Genital Mutilation Act. 2003. www.opsi.gov.uk/acts/acts2003/20030031.htm\#1

Fodor, E. M. 2006. "Right-Wing Authoritarianism and Managerial Assessment of a Schizophrenic Candidate." Journal of Applied Social Psychology 36 (4): 953-978.

Garfinkel, H. 1967. "What is Ethnomethodology?" In Studies in Ethnomethodology. New York: Prentice-Hall.

Gross, R. E., J. Randolph, and J. F. Crigler. 1966. "Clitorectomy for Sexual Abnormalities: Indications and Technique." Surgery 59 (2): 300-308.

Guiné, A., and F. J. M. Fuentes. 2007. "Engendering Redistribution, Recognition, and Representation: The Case of Female Genital Mutilation (FGM) in the United Kingdom and France." Politics \& Society 35 (3): 477-519.

Hegarty, P., and C. Chase. 2000. "Intersex Activism, Feminism and Psychology: Opening a Dialogue on Theory, Research and Clinical Practice." Feminism \& Psychology 10 (1): 117-132.

Hegarty, P., A. Smith, and T. Bogan-Carey. 2019. "Stigma as Framed on YouTube: Effects of Personal Experiences Videos on Students' Beliefs about Medicalizing Intersex." Journal of Applied Social Psychology 49 (3): 133-144.

Hegarty, P., L. Donnelly, P. F. Dutton, S. Gillingham, V. Vecchietti, and K. Williams. Forthcoming. "Understanding of Intersex: The Meanings of Umbrella Terms and Opinions about Medical and Social Responses among Lay People in the USA and UK." Psychology of Sexual Orientation and Gender Diversity.

Human Rights Watch. 2017. "I want to be like Nature Made Me: Medically Unnecessary Surgeries on Intersex Children in the US." http://www.hrw.org/report/2017/07/25/i-want-be-naturemade-me/medically-unnecessary-surgeries-intersex-children-us.

lannello, P., A. Mottini, S. Tirelli, S. Riva, and A. Antonietti. 2017. "Ambiguity and Uncertainty Tolerance, Need for Cognition, and Their Association with Stress. A Study among Italian Practicing Physicians." Medical Education Online 22 (1): 1270009.

Jost, J. T., and A. W. Kruglanski. 2002. "The Estrangement of Social Constructionism and Experimental Social Psychology: History of the Rift and Prospects for Reconciliation." Personality and Social Psychology Review 6 (3): 168-187.

Jost, J. T., J. Glaser, A. W. Kruglanski, and F. J. Sulloway. 2003. "Political Conservatism as Motivated Social Cognition." Psychological Bulletin 129 (3): 339-375.

Karkazis, K. 2008. Fixing Sex: Intersex, Medical Authority, and Lived Experience. Durham, NC: Duke University Press.

Kessler, S. J. 1998. Lessons from the Intersexed. New Brunswick, NJ: Rutgers University Press.

Kruglanski, A.W. 1996. "A Motivated Gatekeeper of Our Minds: Need-for-Closure Effects on Interpersonal and Group Processes." In Handbook of Motivation and Cognition, Volume 3: The Interpersonal Context, edited by Richard M. Sorrentino and E. Tory Higgins, 465-496. New York: Guildford Press.

Lee, P. A., C. P. Houk, S. Faisal Ahmed, I. A. Hughes, and International Consensus Conference on Intersex organized by the Lawson Wilkins Pediatric Endocrine Society and the European Society for Paediatric Endocrinology. 2006. "Consensus Statement on Management of Intersex disorders. International Consensus Conference on Intersex." Pediatrics 118 (2): e488-e500.

Liao, L.-M., and M. Simmonds. 2014. "A Values-Driven and Evidence-Based Health Care Psychology for Diverse Sex Development." Psychology \& Sexuality 5 (1): 83-101. 
Liao, L.-M., P. Hegarty, S. Creighton, T. Lundberg, and K. Roen. 2019. "Clitoral Surgery on Minors: An Interview Study with Clinical Experts of Differences of Sex Development." BMJ Open 9 (6): e025821.

Lundberg, T., K. Roen, A. L. Hirschberg, and L. Frisén. 2016. "It's Part of Me, Not All of Me: Young Women's Experiences of Receiving a Diagnosis Related to Diverse Sex Development." Journal of Pediatric and Adolescent Gynecology 29 (4): 338-343.

Lundberg, T., P. Hegarty, and K. Roen. 2018. "Making Sense of 'Intersex'and 'DSD': How Laypeople Understand and Use Terminology." Psychology \& Sexuality 9 (2): 161-173.

Markus, H. R., and S. Kitayama. 2010. "Cultures and Selves: A Cycle of Mutual Constitution." Perspectives on Psychological Science 5 (4): 420-430.

Mavor, K. I., W. R. Louis, and C. G. Sibley. 2010. "A Bias-Corrected Exploratory and Confirmatory Factor Analysis of Right-Wing Authoritarianism: Support for a Three-Factor Structure." Personality and Individual Differences 48 (1): 28-33.

Michala, L., L.-M. Liao, D. Wood, G. S. Conway, and S. M. Creighton. 2014. "Practice Changes in Childhood Surgery for Ambiguous Genitalia?" Journal of Pediatric Urology 10 (5): 934-939.

Minto, C. L., L.-M. Liao, C. R. Woodhouse, P. G. Ransley, and S. M. Creighton. 2003. "The Effect of Clitoral Surgery on Sexual Outcome in Individuals Who Have Intersex Conditions with Ambiguous Genitalia: A Cross-Sectional Study." The Lancet 361 (9365): 1252-1257.

Moghaddam, F. M., and V. Vuksanovic. 1990. "Attitudes and Behavior toward Human Rights across Different Contexts the Role of Right-Wing Authoritarianism, Political Ideology, and Religiosity." International Journal of Psychology 25 (2): 455-474.

Norton, A. T., and G. M. Herek. 2013. "Heterosexuals' Attitudes toward Transgender People: Findings from a National Probability Sample of US Adults." Sex Roles 68 (11-12): 738-753.

Nunnally, J. C., and I. Bernstein. 1978. Psychometric Theory. New York: McGraw-Hill.

Open Science Collaboration. 2012. "An Open, Large-Scale, Collaborative Effort to Estimate the Reproducibility of Psychological Science." Perspectives on Psychological Science 7 (6): 657-660.

Pasterski, V., P. Prentice, and I. A. Hughes. 2010. "Consequences of the Chicago Consensus on Disorders of Sex Development (DSD): Current Practices in Europe." Archives of Disease in Childhood 95 (8): 618-623.

Prentice, D. A., and D. T. Miller. 1996. "Pluralistic Ignorance and the Perpetuation of Social Norms by Unwitting Actors." Advances in Experimental Social Psychology 28: 161-210.

Rattazzi, A. M. M., A. Bobbio, and L. Canova. 2007. "A Short Version of the Right-Wing Authoritarianism (RWA) Scale." Personality and Individual Differences 43 (5): 1223-1234.

Reisel, D., and S. Fraser. 2016. "Constructing the Female Body: Using Female Genital Mutilation Law to Address Genital-Normalizing Surgery on Intersex Children in the United States." International Journal of Human Rights in Healthcare 9 (1): 62-72.

Roen, K. 2008. "But We Have to Do Something': Surgical 'Correction' of Atypical Genitalia." Body \& Society 14 (1): 47-66.

Roen, K. 2019. "Intersex or Diverse Sex Development: Critical Review of Psychosocial Health Care Research and Indications for Practice." Journal of Sex Research 56 (4-5): 511-528.

Roen, K., S. M. Creighton, P. Hegarty, and L.-M. Liao. 2018. "Vaginal Construction and Treatment Providers' Experiences: A Qualitative Analysis." Journal of Pediatric and Adolescent Gynecology 31 (3): 247-251.

Roen, K., and P. Hegarty. 2018. "Shaping Parents, Shaping Penises: How Medical Teams Frame parents' decisions in response to hypospadias." British Journal of Health Psychology 23 (4): 967-981.

Roets, A., and A. Van Hiel. 2011. "Item Selection and Validation of a Brief, 15-Item Version of the Need for Closure Scale." Personality and Individual Differences 50 (1): 90-94.

Spears, R., and H. J. Smith. 2001. "Experiments as Politics." Political Psychology 22 (2): 309-330.

Streuli, J. C., E. Vayena, Y. Cavicchia-Balmer, and J. Huber. 2013. "Shaping Parents: Impact of Contrasting Professional Counseling on Parents' Decision Making for Children with Disorders of Sex Development." The Journal of Sexual Medicine 10 (8): 1953-1960.

Tamar-Mattis, A. 2006. "Exceptions to the Rule: Curing the Law's Failure to Protect Intersex Infants." Berkeley Journal of Gender, Law and Justice 21(1): 59. 
Tee, N., and P. Hegarty. 2006. "Predicting Opposition to the Civil Rights of Trans Persons in the United Kingdom." Journal of Community \& Applied Social Psychology 16 (1): 70-80. doi:10. 1002/casp.851

UNICEF. 2005. "Changing a Harmful Social Convention: Female Genital Mutilation/Cutting." Innocenti Digest, 12. http://www.unicef-irc.org/publications/396-changing-a-harmful-social-convention-female-genital-mutilation-cutting.html

United Nations Human Rights Campaign fact sheet on Intersex. 2015. http://interactadvocates. org/new-un-intersex-fact-sheet/

UN General Assembly. 1948. "Universal Declaration of Human Rights." 217 (III) A. Paris. http:// www.un.org/en/universal-declaration-human-rights/

Wiesemann, C., S. Ude-Koeller, G. H. G. Sinnecker, and U. Thyen. 2010. "Ethical Principles and Recommendations for the Medical Management of Differences of Sex Development (DSD)/ Intersex in Children and Adolescents." European Journal of Pediatrics 169 (6): 671-679.

World Health Organization (WHO). 2008. "Eliminating Female Genital Mutilation: An Interagency Statement-OHCHR, UNAIDS, UNDP, UNECA, UNESCO, UNFPA, UNHCR, UNICEF, UNIFEM, WHO." http://www.who.int/reproductivehealth/publications/fgm/9789241596442/en/

Yogyakarta Principles. 2017. "The Yogyakarta Principles Plus 10: Additional Principles and State Obligations on the Application of International Human Rights Law in Relation to Sexual Orientation, Gender Identity, Gender Expression and Sex Characteristics, to Complement the Yogyakarta Principles." United Nations, Geneva. http://yogyakartaprinciples.org/principles-en/ yp10/ 